\title{
Correction to: Bad company objection to Joongol Kim's adverbial theory of numbers
}

\author{
Namjoong Kim ${ }^{1}$
}

Published online: 8 March 2018

(C) Springer Science+Business Media B.V., part of Springer Nature 2018

\section{Correction to: Synthese https://doi.org/10.1007/s11229-017-1602-x}

Unfortunately, there is a typo in the author name. The correct spelling is Namjoong Kim. The author name was updated in the original publication.

The original article can be found online at https://doi.org/10.1007/s11229-017-1602-x.

$凶 \quad$ Namjoong Kim

newitx@gmail.com

1 Department of Philosophy, Gyeongsang National University, Jinjoosi, Republic of Korea 